Article

\title{
Antifouling Membranes Based on Cellulose Acetate (CA) Blended with Poly(acrylic acid) for Heavy Metal Remediation
}

\author{
Ibtissem Ounifi ${ }^{1,2}$, Youssef Guesmi ${ }^{1,2, *}$, Claudia Ursino ${ }^{3}$, Sergio Santoro ${ }^{4} \oplus$, Selim Mahfoudhi ${ }^{1}$, \\ Alberto Figoli ${ }^{3, *} \mathbb{0}$, Ezzedin Ferjanie ${ }^{5}$ and Amor Hafiane ${ }^{1}$ \\ 1 Laboratory, Water, Membrane and Environmental Biotechnology, Centre of Research and Water Technologies, \\ Technopark of Borj-Cedria, BP 273, Soliman 8020, Tunisia; ibtissemounifi@yahoo.com (I.O.); \\ mahfoudhiselim@gmail.com (S.M.); amor.hafiane@certe.rnrt.tn (A.H.) \\ 2 Faculty of Sciences of Tunis, University of Tunis-El Manar, 20 Tolede Street, Tunis 2092, Tunisia \\ 3 Institute on Membrane Technology (ITM-CNR), Via P. Bucci 17c, 87036 Rende, CS, Italy; c.ursino@itm.cnr.it \\ 4 Department of Environmental Engineering (DIAm), Università della Calabria, Via Pietro Bucci, Cubo 44/A, \\ 87036 Rende, CS, Italy; sergio.santoro@unical.it \\ 5 Higher Institute of Sciences and Technology of Environment of Borj Cedria, Bp 2050 Borj-Cedria, \\ Hammam Lif 2084, Tunisia; ezzferj@yahoo.com \\ * Correspondence: youssef.kasmi@fst.utm.tn (Y.G.); a.figoli@itm.cnr.it (A.F.)
}

check for

updates

Citation: Ounifi, I.; Guesmi, Y.;

Ursino, C.; Santoro, S.; Mahfoudhi, S.;

Figoli, A.; Ferjanie, E.; Hafiane, A.

Antifouling Membranes Based on

Cellulose Acetate (CA) Blended with

Poly(acrylic acid) for Heavy Metal

Remediation. Appl. Sci. 2021, 11, 4354.

https://doi.org/10.3390/app

11104354

Academic Editor: Mirko Magni

Received: 10 April 2021

Accepted: 5 May 2021

Published: 11 May 2021

Publisher's Note: MDPI stays neutral with regard to jurisdictional claims in published maps and institutional affiliations.

Copyright: (c) 2021 by the authors. Licensee MDPI, Basel, Switzerland. This article is an open access article distributed under the terms and conditions of the Creative Commons Attribution (CC BY) license (https:/ / creativecommons.org/licenses/by/ $4.0 /)$.
Abstract: Fouling has been widely recognized as the Achilles' heel of membrane processes and the growing perception about the relevance of this critical issue has driven the development of advanced antifouling strategies. Herein, novel fouling-resistant ultrafiltration (UF) membranes for Cadmium (Cd) remediation were developed via a blending method by combining the flexibility of cellulose acetate (CA) with the complex properties of poly (acrylic acid) (PAA). A systematic characterization, based on differential scanning calorimetry (DSC) and Fourier Transform Infrared Spectroscopy (FTIR), confirmed the homogeneity of the blend favored by hydrogen interconnections between CA and PAA polymeric chains. The concentration of PAA with respect to CA played a key role in tuning the morphology and the hydrophilic character of the novel UF membranes prepared via non-solvent-induced phase separation (NIPS). UF experiments revealed the tremendous advantages of the blend since CA/PAA membranes showed superior performance with respect to the neat CA membrane in terms of (i) water permeability; (ii) Cd rejection; and (iii) antifouling resistance to humic acid (HA). Concisely, the increasing of the concentration of PAA in the casting solution was found to be beneficial to improve the flux recovery ratio (FRR) coupled with the decline of the total fouling ratio (Rt). Overall, PAA is an effective additive to prepare CA membranes with enhanced antifouling properties exploitable for the remediation of water bodies contaminated by heavy metals via UF process.

Keywords: ultrafiltration membrane; blend; cellulose acetate; humic acid; antifouling membrane; heavy metal removal

\section{Introduction}

During the past decade, pressure-driven membrane processes have been gaining more attention as a sustainable and efficient technology for water treatment to address the global challenges related to water scarcity and the pollution of aquatic environments [1]. In this scenario, ultrafiltration (UF) is a well-established technology for the purification of contaminated water bodies enabling an efficient and cost-saving low-pressure filtration. In fact, compactness, modularity, easy automation and high removal rate of turbidity, organic matters (such as humic substances), and viruses are the main features of UF process highly desired in a wide range of industrial applications [2-4]. The mechanism of separation in UF is basically governed by the pore size exclusion impaired by the trade-off between selectivity and permeability; thus, UF membranes (pore size from $20 \mathrm{~nm}$ to $0.1 \mu \mathrm{m}$ ) are ineffective in rejecting small molecules and ions, such as heavy metals $[5,6]$. 
Nevertheless, functional water-soluble polymers with reasonably high molecular weights are exploited as heavy-metal-binding macro-ligands, resulting in complexes easily rejected by UF membranes [7]. The drawbacks of this approach are: (i) the disposal of the by-products of water treatment consisting in heavy metals enriched slurries [8]; and (ii) membrane fouling, negatively impacting on the cost of the process (energy, operation, and maintenance), the lifespan of the membrane, and the performance of the filtration unit [9]. In fact, fouling is basically caused by adsorption, precipitation, or sedimentation of large metal-polymer complexes on the membrane surface generating a cake layer and/or blocking the pores, thus compromising the permeability of the membrane [10].

Definitively, future perspectives should be aligned towards the development of the next generation of antifouling UF membranes [11,12]. Different strategies have been adopted for fouling mitigation, such as the chemical or physical surface modification of UF membranes (i.e., layer by layer, dip-coating, and plasma treatment) at the expense of a decline in permeability due to pore and porosity constriction [13-18]. Moreover, concerns have arisen regarding the feasibility of membrane modification strategies on a large scale due to a lack of uniformity, reproducibility, stability, process control, and reasonable cost [19].

Polymer blending emerged as a simple, scalable, and economically viable method to produce a single-step high-performance membrane with antifouling behavior [20]. For instance, the blending of poly (vinylidene fluoride) (PVDF) with a quaternary ammonium compound assembled on carbon material was considered an effective strategy to fabricate anti-biofouling membranes for water and wastewater treatment [21]. Polystyrene (PS) with poly(methyl methacrylate) (PMMA) showed excellent results in controlling and hindering membrane biofouling [22], and poly (methyl methacrylate-co-2-hydroxyethyl methacrylate) blended with PVDF was studied for selective adsorption of Ru(III) [23].

Cellulose acetate (CA) has been extensively studied in UF membranes preparation because of its processability, biocompatibility, hydrophilicity, and low price, but its practical exploitation has been hampered by the absence of reactive functional groups on the polymer backbones responsible for selective interactions. On the other hand, poly (acrylic acid) (PAA) has been widely recognized as an ideal complexing agent for heavy metals thanks to a large number of carboxyl groups allowing one to efficiently adsorb or chelate heavy metal ions [24,25]. Additionally, few studies have been focused on the evaluation of the PAA in membrane processes employed in heavy metal removal [26].

Herein, PAA was blended with CA for the preparation of UF membranes via nonsolvent-induced phase separation (NIPS). The study aims to elucidate the effects of the PAA on physicochemical properties of CA membranes with a special focus on the impact of the blended PAA/CA membranes in the Cadmium $(\mathrm{Cd})$ remediation.

Overall, the blending of PAA/CA addresses two main issues associated with UF membranes: (i) mitigation of the fouling phenomena and (ii) the improvement of the efficiency of the CA membrane on heavy metal rejection.

\section{Materials and Methods}

\subsection{Materials}

Cellulose acetate (CA) (MW $=30,000 \mathrm{~g} / \mathrm{mol}$ ) and poly (acrylic acid) (PAA, $\mathrm{MW}=100,000 \mathrm{~g} / \mathrm{mol}, 35 \mathrm{wt}$. \%), acetone, formamide, cadmium sulfate $\left(\mathrm{CdSO}_{4}\right)$, hydrochloric acid, and sodium hydroxide solutions were purchased from Sigma Aldrich. Humic acid (HA) was supplied by LOBA Chemie. All the chemicals were used without any further purification.

\subsection{Membrane Preparation}

Polymeric dopes solutions were prepared dissolving both CA and PAA in a mixture of solvents (acetone/formamide: 2/1). The total polymer concentration was fixed at $18 \mathrm{wt} . \%$, according to our previous study [27], whereas the percentage of PAA with respect to the polymer content was varied from $0 \mathrm{wt}$. $\%$ to $15 \mathrm{wt}$. $\%$. Then, the solutions were magnetically 
stirred for $4 \mathrm{~h}$ at room temperature until the complete dissolution of the polymers and subsequently degassed for $24 \mathrm{~h}$. Finally, the dope solutions were cast successively onto a glass plate with a casting knife set at $200 \mu \mathrm{m}$ of thickness and immersed in a water coagulation bath, at room temperature, according to NIPS process $[28,29]$. The obtained membranes were washed for $10 \mathrm{~min}$ using distilled water at room temperature and in a second step at $60^{\circ} \mathrm{C}$ in order to remove the residual traces of solvents. Table 1 summarized the composition of the blends employed to prepared CA and CA/PAA UF membranes.

Table 1. Composition of the polymeric solutions employed for membranes preparation.

\begin{tabular}{ccc}
\hline \multirow{2}{*}{ Membrane Name } & \multicolumn{2}{c}{ Blend Composition } \\
\cline { 2 - 3 } & CA wt. \% & PAA wt. \% \\
\hline M0 & 100 & 0 \\
\hline M8 & 92 & 15 \\
\hline M15 & 85 &
\end{tabular}

\subsection{Membrane Characterization}

- Fourier Transform infrared spectroscopy (FTIR)

The chemical structures of the CA and CA/PAA membranes were investigated by Fourier Transform infrared spectroscopy (FTIR) (IRAffinit-1S, Shimadzu Corporation s.r.l., Kadikoy-Istanbul, Turkey) in the spectral range of $4000-400 \mathrm{~cm}^{-1}$. Five different points in the membranes sample were analyzed. The spectra were obtained with a resolution of $0.5 \mathrm{~cm}^{-1}$.

\section{- $\quad$ Scanning Electron Microscopy (SEM)}

CA and CA/PAA UF membranes morphology were analyzed via scanning electron microscopy (Zeiss EVO MA 100, Assing, Italy). SEM pictures of both the membranes surface (top and bottom side) and cross section pictures were acquired. In particular, cross section samples were prepared fractured the membrane in liquid nitrogen. Before the observation, the samples were sputter-coated with a thin gold film using a rotary pumped coater (Quorum Q150R S, Quorumtech, Lewes, UK).

- Differential Scanning Calorimetry (DSC)

Further investigations on the properties of the CA-PAA blend were carried-out by studying the thermal behaviour of the prepared membranes in terms of glass transition temperature $(\mathrm{Tg})$, melting temperature $(\mathrm{Tm})$, and degradation temperature $(\mathrm{Td})$, measured by differential scanning calorimetry (Heat flux DSC 4000, Perkin-Elmer, Japan). The samples were heated from $0{ }^{\circ} \mathrm{C}$ to $450{ }^{\circ} \mathrm{C}$ at a controlled heating rate of $10^{\circ} \mathrm{C} / \mathrm{min}$, with accuracy of $\pm 0.1{ }^{\circ} \mathrm{C}$ and precision $\pm 0.02{ }^{\circ} \mathrm{C}$.

- Contact Angle

CA and CA/PAA UF membranes' hydrophilicity was evaluated using attension theta automated optical tensiometer (ATA Scientific, Taren Point, Australia). Ten measurements for each membrane were performed using ultra-pure water ( $5 \mu \mathrm{L}$, volume of the drop), at room temperature. The average values and the standard deviations were reported.

- Water Content (\%)

The water content of the membranes (affinity towards water) was estimated through a series of gravimetric measurements according to protocol already described in literature [30]. Membrane samples were initially cut $\left(1 \mathrm{~cm}^{2}\right)$ and then immersed in deionized water for $24 \mathrm{~h}$ at room temperature. Subsequently, the wet samples were weighted $\left(\mathrm{W}_{\mathrm{w}}\right)$, 
dried for $48 \mathrm{~h}$ at $60^{\circ} \mathrm{C}$, and weighted once again $\left(\mathrm{W}_{\mathrm{d}}\right)$. The percentage of water content was calculated using the Equation (1):

$$
\% \text { Water uptake }=\frac{\mathrm{W}_{\mathrm{w}}-\mathrm{W}_{\mathrm{d}}}{\mathrm{W}_{\mathrm{w}}} \times 100
$$

For each membrane, three measurements were performed and the average values and corresponding standard deviation were calculated and reported.

- $\quad$ Porosity (\%) and Pore Size

CA and CA/PAA UF membrane porosity $(\varepsilon)$ was determined by gravimetric method [29,31], employing Equation (2):

$$
\varepsilon=\frac{\mathrm{W}_{\mathrm{w}}-\mathrm{W}_{\mathrm{d}}}{\mathrm{A} \times 1 \times \rho} \times 100
$$

where $\mathrm{A}, 1$, and $\rho$ are the membrane filtration area $\left(\mathrm{cm}^{2}\right)$ and the thickness $(\mathrm{cm})$ of membrane and the density of water $\left(0.998 \mathrm{~g} \mathrm{~cm}^{-3}\right)$, respectively. In addition, the mean pore radius was performed through the Guerout-Elford-Ferry equation (Equation (3)) [32]:

$$
\mathrm{r}_{\mathrm{m}}=\sqrt{\frac{(2.9-1.75) 8 \eta 1 \mathrm{Q}}{\varepsilon \mathrm{A} \Delta \mathrm{P}}}
$$

where $\varepsilon(\%)$ is the average porosity of the membrane, $\eta$ is the water viscosity $\left(8.9 \times 10^{-4} \mathrm{~Pa} \mathrm{~s}\right)$, 1 is the membrane thickness $(\mathrm{m}), \mathrm{Q}$ is the volume of permeate water per unit time $\left(\mathrm{m}^{3} \mathrm{~s}^{-1}\right)$, and $\mathrm{A}$ is the membrane effective area $\left(\mathrm{m}^{2}\right)$ and $\Delta \mathrm{P}(\mathrm{MPa})$ the operational pressure. The average and the corresponding standard deviation for porosity and pore size measures were reported.

\subsection{Pure Water Permeability and Anti-Fouling Tests}

Ultrafiltration tests were conducted using a pressurized nitrogen gas dead-end cell filtration system (Millipore). The total volume of the cell was $350 \mathrm{~mL}$, with an effective area of $28.26 \mathrm{~cm}^{2}$. The experiments were performed at room temperature, and the feed was stirred at $110 \mathrm{rpm}$. Before the test, the membrane was compacted for $30 \mathrm{~min}$ at 5 bar with distilled water. The operative pressure was varied from 1 to 5 bar; each test was anticipated by a stabilization period of $10 \mathrm{~min}$. The permeate was collected every $5 \mathrm{~min}$ for $1 \mathrm{~h}$, and flux was calculated according to Equation (4):

$$
\mathrm{J}_{\mathrm{w}}=\frac{\mathrm{V}}{\mathrm{A} \times \mathrm{t}}
$$

where $J_{\mathrm{W}}$ is the water flux $\left(\mathrm{L} \mathrm{m}^{-2} \mathrm{~h}^{-1}\right), \mathrm{V}$ is the of permeate volume $(\mathrm{L}), \mathrm{A}$ is the membrane area $\left(\mathrm{m}^{2}\right)$, and $\mathrm{t}$ is the time $(\mathrm{h})$.

To measure the rejection and anti-fouling efficiency of the membranes, solutions of humic acid (HA) at a concentration of $100 \mathrm{mg} \mathrm{L}^{-1}$ were employed as feed and the flux $\left(\mathrm{J}_{\mathrm{HA}}\right)$ was calculated again. The physicochemical properties of the HA solution are reported in Table 2.

Table 2. Physicochemical Properties of HA solution (determined by Zetasizer Nano ZS90, Nanoparticle Size Analyzer, Tokyo, Japan).

\begin{tabular}{cccc}
\hline $\begin{array}{c}\text { Concentration } \\
{[\mathrm{mg} / \mathrm{L}]}\end{array}$ & $\mathrm{pH}$ & $\begin{array}{c}\text { Zeta Potential } \\
{[\mathrm{mV}]}\end{array}$ & $\begin{array}{c}\text { Particle Size in Suspension } \\
{[\mathrm{nm}]}\end{array}$ \\
\hline 100 & 6 & $-27.1 \pm 0.01$ & $532.7 \pm 4.5$ \\
\hline
\end{tabular}


Then, the fouled membranes were washed with deionized water for $30 \mathrm{~min}$ and the recovered flux $\left(\mathrm{J}_{\mathrm{w} 2}\right)$ was registered in order to evaluate the water permeability decline due to the irreversible fouling.

Several UF experiments were carried out to study the fouling tendency of CA and PAA/CA membranes and their long-term performance stability. Three cycles of $240 \mathrm{~min}$ were performed by altering pure water $(120 \mathrm{~min})$ and HA solution $(120 \mathrm{~min})$ as feed to investigate the degree of reversibility of the performance of the developed UF membranes.

In order to characterize the anti-fouling performance of the membrane, some parameters were observed and calculated according to the relative formulas:

$$
\begin{gathered}
\operatorname{FRR}(\%)=\frac{\mathrm{J}_{\mathrm{w} 2}}{\mathrm{~J}_{\mathrm{w}}} * 100 \\
\operatorname{Rr}(\%)=\frac{\left(\mathrm{J}_{\mathrm{w} 2}-\mathrm{J}_{\mathrm{HA}}\right)}{\mathrm{J}_{\mathrm{w}}} * 100 \\
\operatorname{Rir}(\%)=\frac{\left(\mathrm{J}_{\mathrm{w}}-\mathrm{J}_{\mathrm{w} 2}\right)}{\mathrm{J}_{\mathrm{w}}} * 100 \\
\operatorname{Rt}(\%)=\operatorname{Rr}+\operatorname{Rir}=\left(1-\frac{\mathrm{J}_{\mathrm{HA}}}{\mathrm{J}_{\mathrm{w}}}\right) * 100
\end{gathered}
$$

where FRR (\%) was the flux recovery ratio quantifying the antifouling property after a UF cycle, $\operatorname{Rr}(\%)$ represented the reversible flux decline ratio caused by reversible fouling eliminated by hydraulic cleaning, Rir (\%) estimated the irreversible flux decline ratio, and Rt (\%) described the flux decline ratio caused by HA fouling [33].

During the test performed with HA solution, the absorbance of HA was evaluated using spectrophotometer (PerkinElmer, Waltham, MA, USA) through an excitation-emission matrix (EEM). EEM spectroscopy provides information on the emission (Em) profile concurrently with excitation (Ex) wavelength data, creating a 3-D map of fluorescence characteristics [34]. The samples were diluted 1:5 and analyzed in a quartz cuvette with a path length of $10 \mathrm{~mm}$ maintained at a constant temperature of $20^{\circ} \mathrm{C}$. The EEMs were recorded at $10 \mathrm{~nm}$ intervals for excitation spectra between 190 and $600 \mathrm{~nm}$ and emission spectra between 190 and $600 \mathrm{~nm}$ at an integration time of $0.1 \mathrm{~s}$ with excitation and emission slit of $5 \mathrm{~nm}$ and scan rate of $600 \mathrm{~nm} \mathrm{~min}{ }^{-1}$. The HA rejection ratio was calculated employing the following Equation (9):

$$
\mathrm{R}(\%)=\left(1-\frac{\mathrm{C}_{\mathrm{p}}}{\mathrm{C}_{\mathrm{f}}}\right) \times 100
$$

where $C_{p}$ and $C_{f}$ were the HA concentration of permeate and feed solution, respectively.

\section{Results}

\subsection{Characterization of the Prepared Membranes}

- $\quad$ FTIR and DSC Analysis

Figure 1 shows the FTIR spectra (4000-400 $\mathrm{cm}^{-1}$ ) obtained from the PAA polymer, blank CA membrane (M0), and membranes obtained by blending CA with PAA at 8 wt. \% (M8) and 15 wt. \% (M15), respectively. In particular, PAA spectrum reveals the typical bands for carboxylic acids such as the characteristic stretching absorption of the hydroxyl groups $(\mathrm{O}-\mathrm{H})$ in $3522 \mathrm{~cm}^{-1}$ and the absorption peak characteristic of carbonyl $(\mathrm{C}=\mathrm{O})$ in $1719 \mathrm{~cm}^{-1}$. In addition, the bands that appeared at $1219 \mathrm{~cm}^{-1}$ and $1458 \mathrm{~cm}^{-1}$ can be assigned, respectively, to the C-C stretching and the in-plane bending of the hydroxyl group. The spectrum of M0 membrane presented the distinctive bands of CA ascribable to the stretching of different characteristic functional groups: $\mathrm{O}-\mathrm{H}\left(3250-3700 \mathrm{~cm}^{-1}\right), \mathrm{C}-\mathrm{H}$ $\left(2850-2990 \mathrm{~cm}^{-1}\right), \mathrm{C}=\mathrm{O}\left(1740 \mathrm{~cm}^{-1}\right), \mathrm{C}-\mathrm{H}\left(1372 \mathrm{~cm}^{-1}\right)$ of $-\mathrm{CH}_{3}$, and $\mathrm{C}-\mathrm{O}-\mathrm{C}\left(917 \mathrm{~cm}^{-1}\right)$ of ether $[35,36]$. 


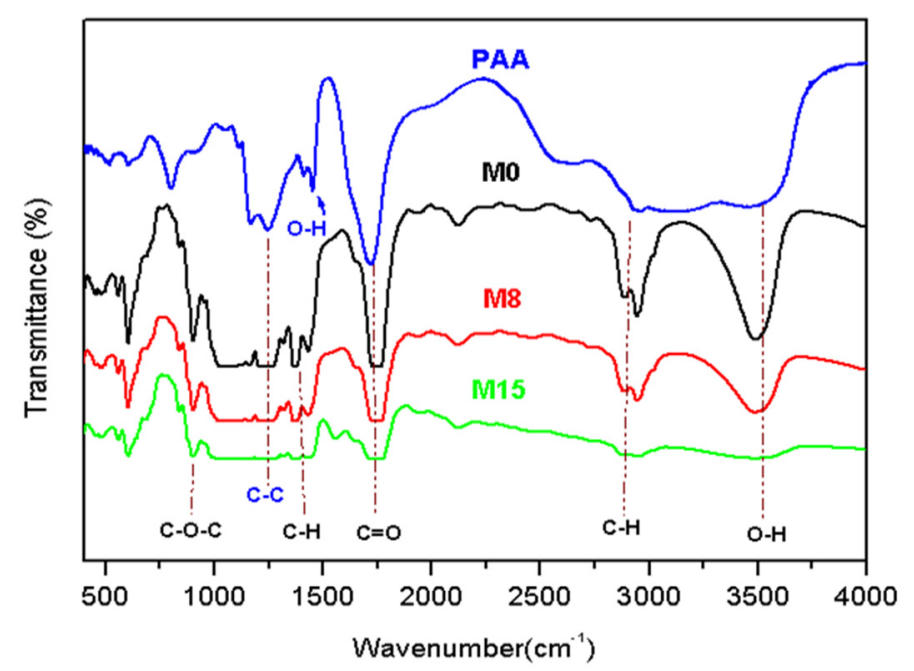

Figure 1. FTIR spectra of pure CA membranes (M0) and CA/PAA blend membranes (M8 and M15).

The FTIR spectrum of the blend membranes M8 and M15 revealed the effect of the presence of PAA on the chemical nature of CA membranes. The enlargement and the remarkable decreasing of the intensity of the band between 3200 and $3700 \mathrm{~cm}^{-1}$ indicated the hydrogen interactions between the two polymers favouring a homogeneous blend. Thus, the bands attributed to the hydroxyl and acetyl groups of CA significantly decrease [37]. Moreover, the bands situated between 1150 and $1500 \mathrm{~cm}^{-1}$ appeared to overlap, which may be due to the interconnection between the two polymers via hydrogen bonding.

DSC is a widely used thermal analytical tool that helps to understand the thermal behavior of polymers. It serves, basically, to identify the compatibility of polymer blends and to detect the different temperatures of phase transitions of the polymers and their blends. The DSC thermogram of PAA and the prepared membranes M0, M8, and M15 are given in Figure $2 \mathrm{a}, \mathrm{b}$. A comparison of the glass transition temperature $(\mathrm{Tg})$, melting temperature $(\mathrm{Tm})$, and degradation temperatures (Td) is summarized in the Table 3. Thermogravimetric analyses are summarized in Table 3, revealing the presence of three thermal events in every sample; two of them are endothermic, as reported in Figure $2 b$.

Table 3. Values of glass transition temperature ( $\mathrm{Tg})$, melting temperature $(\mathrm{Tm})$, and degradation temperature $(\mathrm{Td})$ of the CA and CA/PAA blended membranes.

\begin{tabular}{cccc}
\hline Samples & $\mathbf{T}_{\mathbf{g}}\left[{ }^{\circ} \mathbf{C}\right]$ & $\mathbf{T}_{\mathbf{m}}\left[{ }^{\circ} \mathbf{C}\right]$ & $\mathbf{T}_{\mathbf{d}}\left[{ }^{\circ} \mathbf{C}\right]$ \\
\hline PAA & 44.5 & 147.23 & 252.78 \\
\hline M0 & 63.71 & 231.80 & 369.40 \\
\hline M8 & 65.30 & 227.47 & 362.68 \\
\hline M15 & 64.12 & 226.55 & 361.01 \\
\hline
\end{tabular}

The endothermic peaks were attributed to the glass transition $(\mathrm{Tg})$ and the melting point $(\mathrm{Tm})$, whereas the exothermic peak was due to the polymer degradation (Td). The presence of a single $\mathrm{Tg}$ in M8 and M15, similar to $\mathrm{M} 0\left(63.71^{\circ} \mathrm{C}\right)$, indicated an optimal miscibility between the two polymers. In fact, two well-distinguished glass transition temperatures characteristic of each polymer are usually detected in the case of a heterogeneous blend [38]. Indeed, the compatibility of the two components was assured by the hydrogen interconnections as confirmed by the FTIR result. Moreover, the observed Tg were in the range of $64.51 \pm 0.80^{\circ} \mathrm{C}$ whereas Tm decreased from $231.80^{\circ} \mathrm{C}$ for $\mathrm{M} 0$ to $226.55{ }^{\circ} \mathrm{C}$ for M15, indicating a minimal effect of PAA on the thermal properties of the membranes. Definitely, 
the observed values of $\mathrm{Tg}$ and $\mathrm{Tm}$ were similar to those reported in previous studies for CA membranes $[39,40]$.

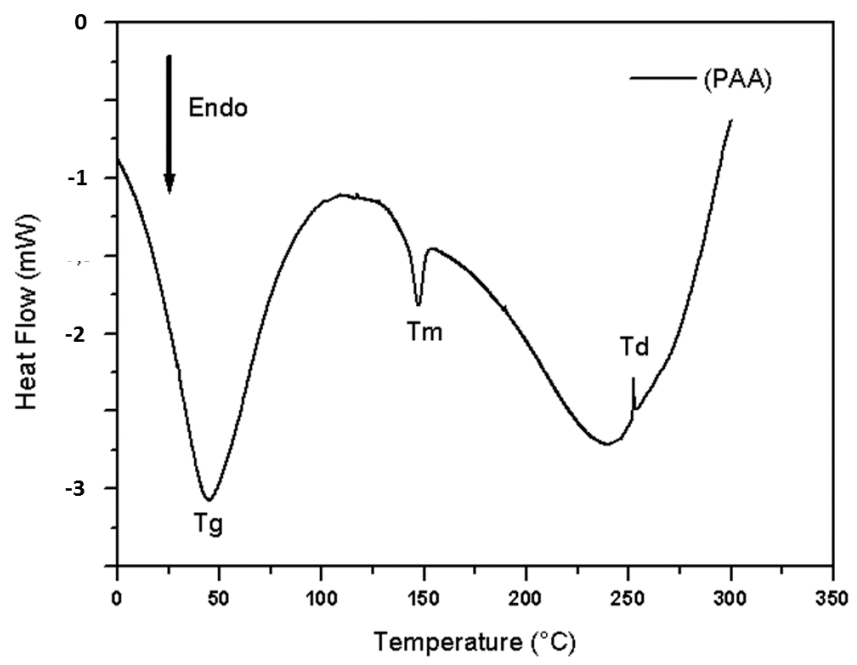

(a)

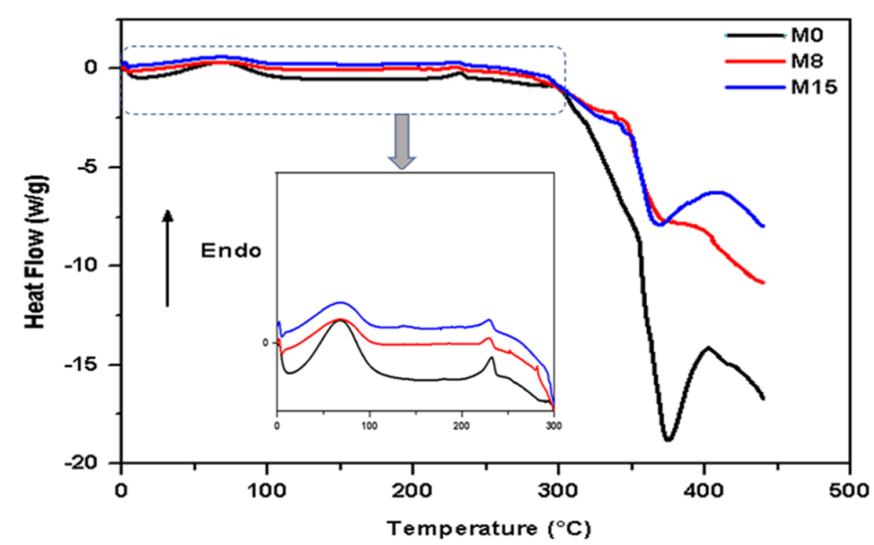

(b)

Figure 2. DSC thermograms of the (a) pure PAA polymer and (b) of the membranes prepared in this work.

\section{- $\quad$ SEM}

Morphology of the membranes surface (top and bottom side) and the relative crosssection of the prepared membranes are shown in Figure 3. It is possible to observe that all the investigated membranes exhibited an asymmetric microstructure including a denser skin top-layer, acting as selective barrier, supported on a porous sub-layer. Moreover, the improvement of PAA concentration from $0 \mathrm{wt}$. \% to $8 \mathrm{wt}$. \% increased the surface porosity of the membrane, reduced the thickness of the skin layer, and turned the morphology of the membrane from finger-like to sponge-like. In fact, the neat CA membrane (M0) presented dense surfaces and macrovoids, whereas the presence of PAA led to the preparation of highly porous membrane. The formation of the skin layer is usually caused by the rapid evaporation of volatile solvents (such as acetone) from the top surface of the nascent membrane during the casting. The consequence is the local increasing of the polymer concentration, leading to the generation of a dense skin layer [31,41]. This dense layer reduced the diffusion of the non-solvent from coagulation bath into polymeric solution resulting in a delayed demixing, leading to the formation of the macrovoids [42]. 

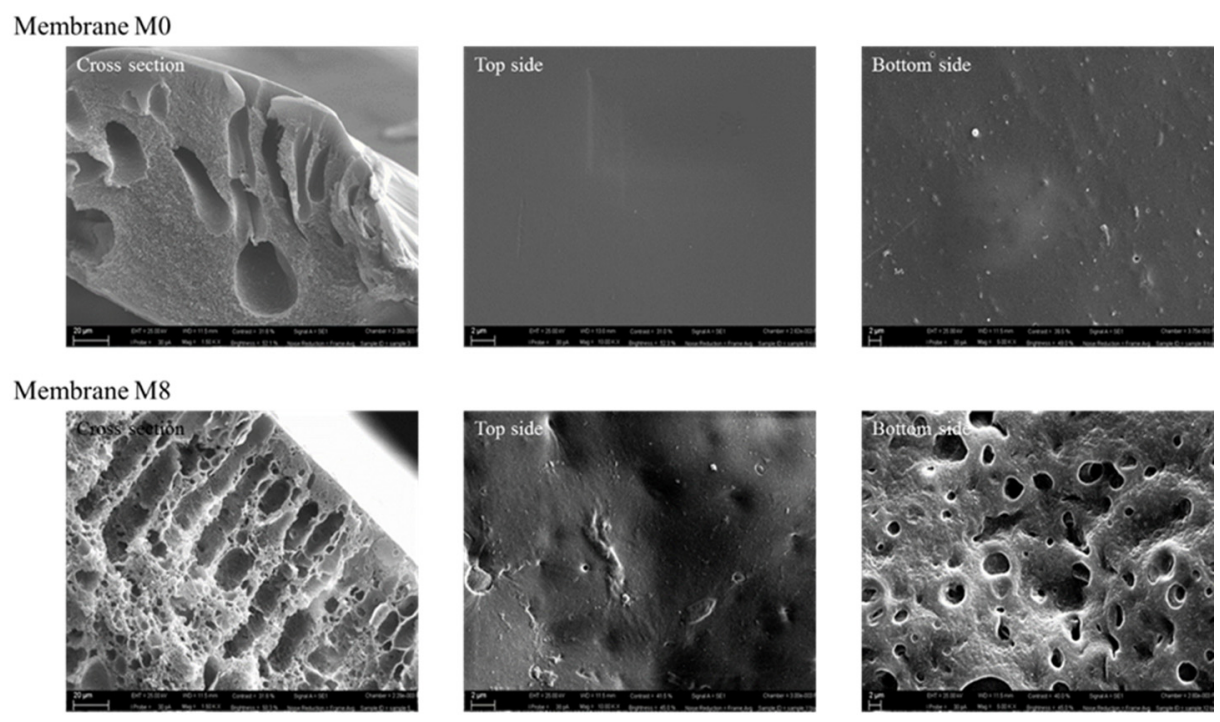

Membrane M15
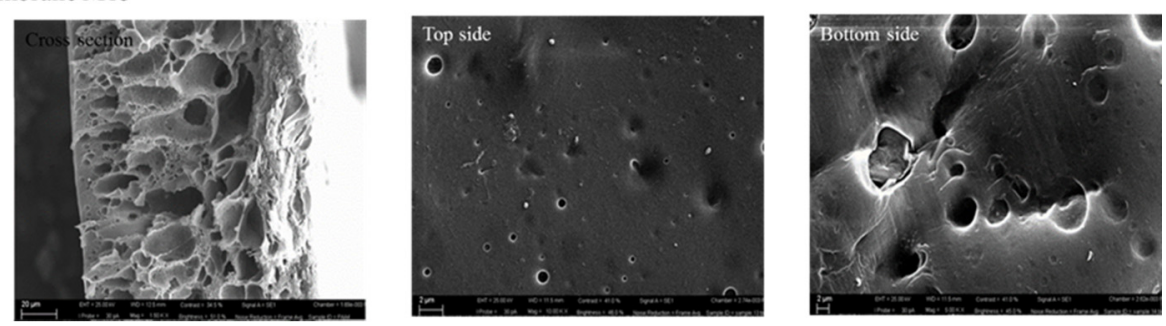

Figure 3. SEM images of neat membrane M0 and the blended membrane M8 and M15 with Magnification of $150 \times$ (cross-section), $1000 \times$ (top surface) and $5000 \times$ (bottom surface).

The composition of the dope solution is a key factor to modulate the membrane morphology by the affinity between the solvent and the non-solvent and the viscosity of the casting solution [43]. PAA is a hydrophilic polymer, and its blend with CA accelerated the exchange rate of the solvent/non-solvent favouring the formation of finger-like microstructure, as observed for M8 [44]. For M15, the higher amount of PAA increased the viscosity of the casting solution, which delayed the exchange rate of the solvent/non-solvent leading to a sponge-like structure [45].

- Porosity, Pore Size, Contact Angle, Water Content and Pure Water Permeability

Measurements of porosity confirmed the outcomes of SEM pictures: the increase of the PAA concentration in the blend raised the total porosity from $44.56 \%$ for $\mathrm{M} 0$ to $75.6 \%$ for M15 (Table 4). On the other hand, the mean pore radius ( $(\mathrm{rm})$ slightly decreased by increasing the PAA from ca. $13 \mathrm{~nm}$ for M0 to ca. $10 \mathrm{~nm}$ for M15 (Table 4).

Table 4. Summary of the CA and CA/PAA blended membranes prepared.

\begin{tabular}{ccccc}
\hline Membranes & Porosity (\%) $*$ & $\mathbf{r}_{\mathbf{m}}[\mathbf{n m}] *$ & $\begin{array}{c}\text { Water Uptake } \\
\mathbf{( \% )} *\end{array}$ & $\begin{array}{c}\mathbf{L}_{\mathbf{p}} \\
\left(\mathbf{L ~ m ~}^{-\mathbf{2}} \mathbf{h}^{-\mathbf{1}} \mathbf{b a r}^{-\mathbf{1}} \mathbf{)} *\right.\end{array}$ \\
\hline M0 & $44.58 \pm 0.2$ & $12.92 \pm 0.02$ & $50.64 \pm 0.12$ & $15.51 \pm 1.2$ \\
\hline M8 & $64.50 \pm 0.4$ & $10.13 \pm 0.02$ & $69.87 \pm 0.24$ & $17.30 \pm 1.4$ \\
\hline M15 & $75.65 \pm 0.7$ & $9.65 \pm 0.03$ & $78.23 \pm 0.1$ & $19.98 \pm 0.5$ \\
\hline
\end{tabular}

The presence of PAA not only affected the membranes morphology but also their chemical-physical properties by improving their hydrophilic character. In fact, the contact angle decreased from $71.55^{\circ}$ for the neat CA membrane (M0) to $37.34^{\circ}$ and $25.04^{\circ}$ for M8 and M15, respectively, (Figure 4). This was mostly due to the enhancement of the 
hydrophilic sites (carboxylic groups) available in the membranes M8 and M15 and provided by the PAA.

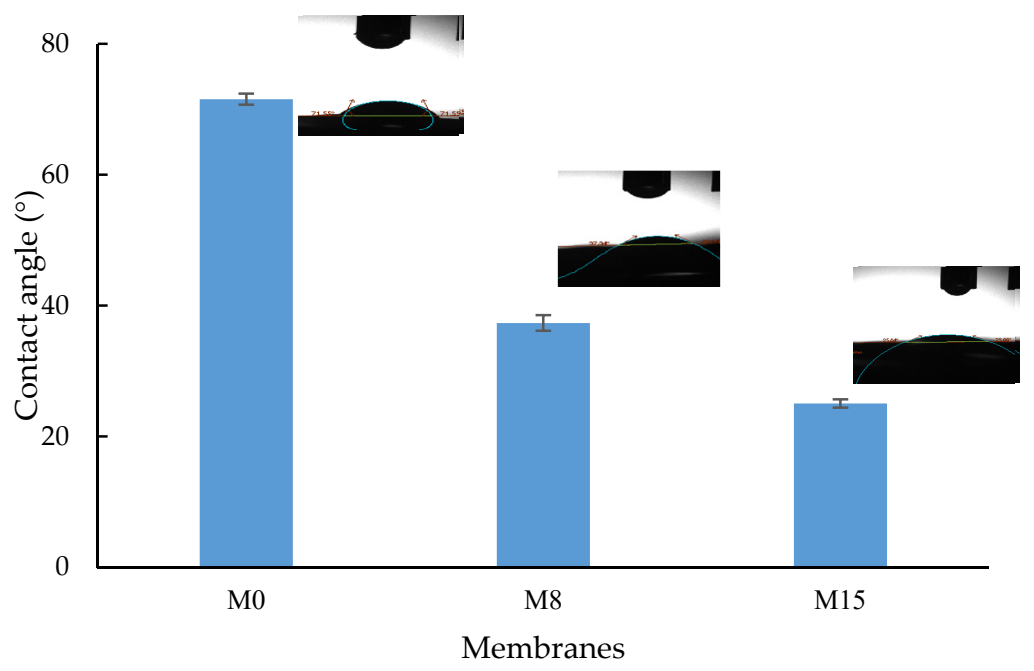

Figure 4. Contact angle of the prepared membrane.

Thus, the addition of the PAA facilitates water diffusion through the membrane by improving the hydrogen bonding interactions [46]. In fact, as reported in Table 4, the maximum water uptake $(78.2 \%)$ was observed for the membrane with the highest PAA amount (M15), whereas the neat CA membrane (M0) showed the lowest water uptake $(50.6 \%)$.

The improvement of both porosity and hydrophilicity favoured the transport of water as confirmed by the values of water membrane permeance (Lp) shown in Table 5. In fact, the pure water flux data illustrated in Figure 5 show that the water flux of the membrane M15 is ca. 20\% higher than the neat CA membrane M0.

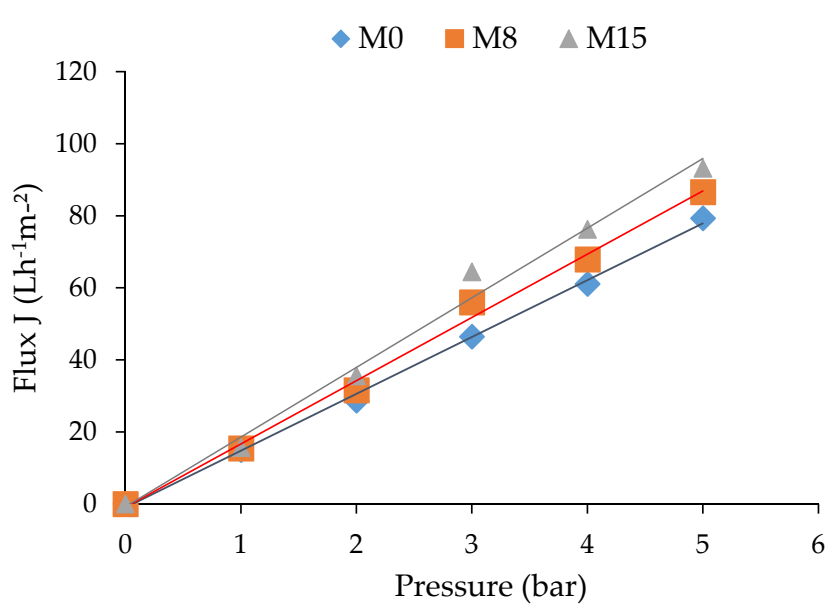

Figure 5. Water flux of the CA and CA/PAA blended membranes.

\subsection{Membrane Performance}

- UF Experiments

The UF performance and the anti-fouling properties of the developed membranes were investigated using $\mathrm{HA}$ as foulant model revealing a rejection superior to $95 \%$. In particular, the measured HA rejections were $95.7 \%, 96.03 \%$, and $99.9 \%$ for M0, M8, and M15, respectively. Hence, the increasing of the PAA amount in the casting solution positively affected the UF performance of CA membranes. 
Figure 6 shows the 2D fluorescence spectra of the studied HA solutions, before (a) and after ultrafiltration membrane process (b, c, and d), not corrected for Rayleigh scattering peaks that appeared in the form of diagonal bands. The presence of HA in the feed caused two regions of fluorescent activity located at around Ex/Em $=265 \mathrm{~nm} / 525 \mathrm{~nm}$ and $\mathrm{Ex} / \mathrm{Em}=360 \mathrm{~nm} / 520 \mathrm{~nm}$ due to the presence of large quantities of aromatic structures and unsaturated fatty chains in humic substances [47], as observed in Figure 6a.
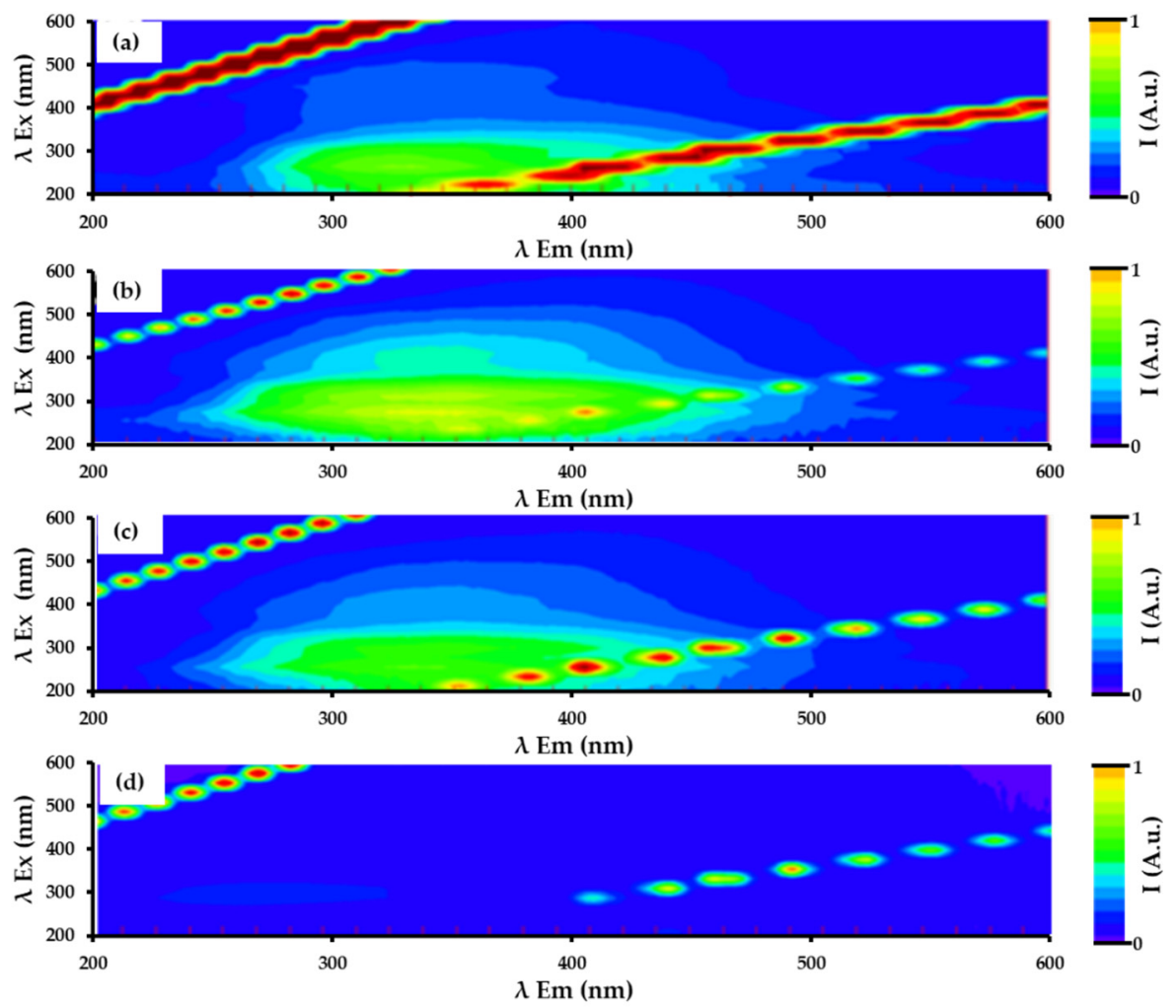

Figure 6. 2D fluorescence spectra of feed (a) and permeates of UF experiments performed with M0 (b), M8 (c), and M15 (d), respectively.

Obviously, the decreasing of the HA in the permeates provoked a diminishing of the fluorescent activities, thus Ex/Em bands were less evident by increasing the rejection. In fact, the results showed that fluorescent activities decreased by increasing the concentration of PAA in the membranes and the emission signal raising from HA disappeared in the permeate collected after the UF processes carried out with the membrane M15 (Figure 6d).

It is well known that the main factors contributing to the separation in the UF process dominated by size-excluding mechanism are the membrane pore size and the steric hinderance of the target contaminants. Thus, the reduction of the pore size from $12.9 \mathrm{~nm}$ to $9.6 \mathrm{~nm}$ by increasing the PAA concentration from $0 \mathrm{wt}$ \% to $15 \mathrm{wt}$. \% with respect to CA positively affected the coefficient of rejection.

Nevertheless, the chemical nature of the membranes played a key role on the separation performance: PAA lead to the incorporation of carboxylic groups, improving rejection via electrostatic repulsions with humic acid components that are negatively charged, as demonstrated by the negative potential zeta $(-27.1 \mathrm{mV})$ reported in Table 2.

- Anti-fouling Properties

Fouling is a critical issue in UF negatively affecting the long-term stability, productivity, and cost of the process. Results summarized in Figure 7 show the benefits of blending CA with PAA in terms of flux and anti-fouling resistance. 


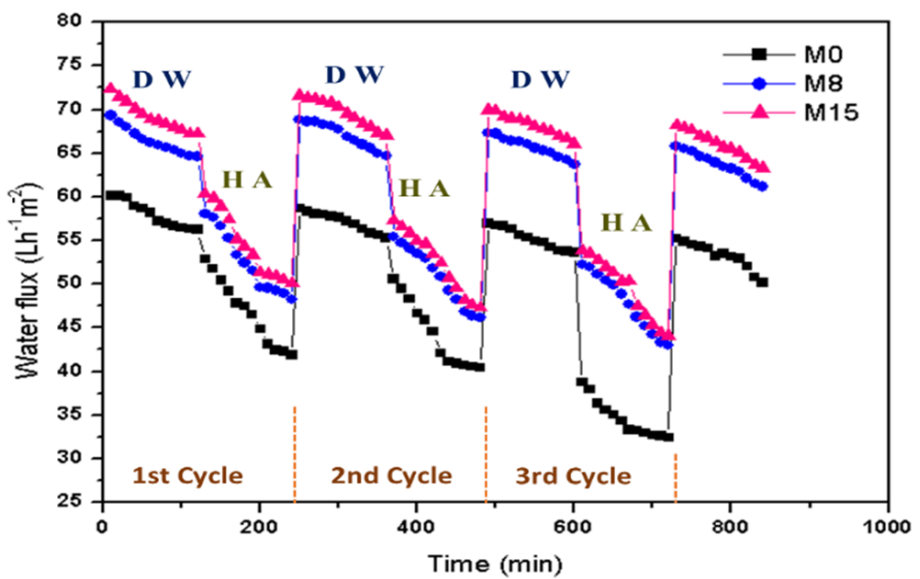

Figure 7. Time versus fluxes during three cycles of the HA UF experiment of the prepared membranes.

In fact, water flux $\left(\mathrm{JW}_{\mathrm{W}}\right)$, HA solution flux $\left(\mathrm{J}_{\mathrm{HA}}\right)$, and water flux after cleaning $\left(\mathrm{JWW}_{\mathrm{W}}\right)$ increased by enhancing the PAA concentration in the blend with CA. Nevertheless, the effect of the presence of HA in the feed solution was a consistent drop in the flux with a reduction in the range of $7-13 \%$. Subsequently, the flux dramatically decreased during the time due to the permeation of water and the consequent improvement of HA concentration in the feed that intensified the concentration polarization and fouling.

The fouling consists of extra resistance to the water permeation as clarified by the Darcy's law, which is useful for quantitatively describing the hydraulic resistance of the membrane $(\mathrm{R})$ from the driving force $(\Delta \mathrm{P})$, the water viscosity $(\mu)$, and the measured permeate flux $(\mathrm{J})$, as follows:

$$
\mathrm{R}=\Delta \mathrm{P} /(\mathrm{J} \times \mu)
$$

The ultimate result of $2 \mathrm{~h}$ of UF practices with a feed solution containing HA (1st Cycle) was an improvement of ca. $26 \%$ compared to the hydraulic resistance of the membrane of M0 caused by the fouling, whereas the impact on the resistance of M15 membrane was of ca. $20 \%$.

Moreover, primary fouling serves active sites for the subsequent deposition of macromolecules on the membrane surface, accelerating the decline of membrane performance over the time [48]. The negative effect of fouling on membrane permeability is related to three mechanisms: (i) pore constriction caused by adsorption of filtered species within the membrane pores, (ii) pore blocking at the membrane surface, and (iii) cake formation due to the species rejected by the membrane [49]. These effects are less evident in M8 and M15 membranes due to the repulsive forces involving the PAA embodied in the membrane and the HA in the feed solution, resulting in the mitigation of the solute deposition on the membrane surface.

Table 5. Comparison of permeate flux, HA rejection, and FRR reported by literatures with prepared membranes in this study.

\begin{tabular}{|c|c|c|c|c|c|}
\hline Membrane & $\begin{array}{l}\text { Pressure } \\
\text { (bar) }\end{array}$ & $\begin{array}{l}\text { Permeate Flux } \\
\left(\mathrm{L} / \mathrm{m}^{2} \cdot \mathrm{h}\right)\end{array}$ & $\begin{array}{c}\text { HA Rejection } \\
(\%)\end{array}$ & $\begin{array}{l}\text { FRR } \\
(\%)\end{array}$ & Reference \\
\hline $\mathrm{PAN} / \mathrm{CS} / \mathrm{Fe}_{3} \mathrm{O}_{4}$ & 5.5 & 25.5 & 96.5 & - & [49] \\
\hline $\mathrm{PES} / \mathrm{PVP} / \mathrm{TiO}_{2}$ & 1 & 21.927 & 92.96 & 99.03 & [50] \\
\hline CA/OMTT & 3 & 160 & 95.4 & - & [51] \\
\hline $\mathrm{RC} / \mathrm{SA}$ & 1 & - & 91 & 67 & [52] \\
\hline M0 & 4 & 61.12 & 95.7 & 88.16 & This work \\
\hline M15 & 4 & 76.29 & 99.9 & 97.65 & This work \\
\hline
\end{tabular}

PAN: Polyacrylonitrile, CS: chitosan; PES: polyethersulfone, PVP: polyvinyl pyrrolidone, CA: Cellulose acetate, OMTT: Organically modified montmorillonite, RC: regenerated cellulose, SA: sulfonic acid. 
To thoroughly investigate the antifouling properties of the membranes, Figure 8 depicts the recovery ratio (FRR) observed during the first two cycles.

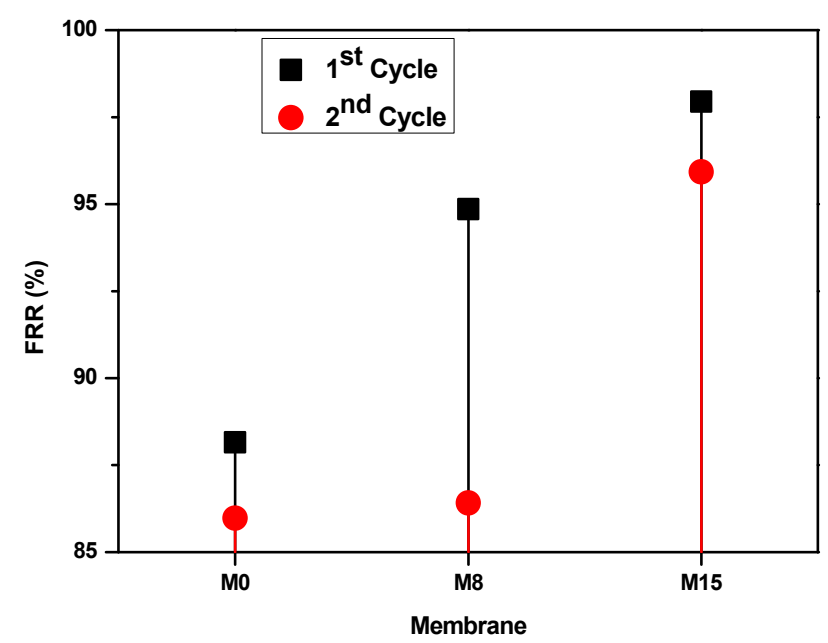

Figure 8. FRR percentages results of the prepared membranes during the first two cycles. Experimental error below than $5 \%$.

The results clearly show the advantage of blending since the FRR improved by increasing the PAA concentration in the membrane. For the first cycle, the FRR was $88.16 \%$ for M0 made of bare CA, which increased to $94.86 \%$ for M8 and reached the remarkable value of $97.65 \%$ for M15 because of the positive effect of the PAA. The same trend was observed during the second cycle: the water flux recovery ratio was $85.98 \%$ for $\mathrm{M} 0,86.41 \%$ for M8, and $95.93 \%$ for M15.

The reversible fouling ratio ( $\mathrm{Rr}$ ) and irreversible fouling ratio (Rir), as well as their sum-total fouling ratio (Rt), were calculated and depicted in Figure 9. The neat CA membrane showed a total fouling ratio of $31.5 \%$ decreasing to $26.7 \%$ for $\mathrm{M} 8$ and to $22 \%$ for M15. However, this decline was mainly due to the reduction of the reversible fouling ratio ( $\mathrm{Rr}$ ), probably related to cake formation, minimized from $23.7 \%$ for M0 to $21.8 \%$ for M8 and to $16.5 \%$ for M15, whereas no relevant effects were observed on the Rir mostly due to HA absorption into the pores and onto the membrane surface. Definitively, the blending of CA with PAA mitigated the fouling largely reversible and facilitated the recovery of the membrane permeability by hydraulic cleaning, but irreversible fouling during long-term operation is still inevitable [50]. A comparison between the present results with some previous studies evidenced the interesting achievements obtained by blending CA with PAA (Table 5).

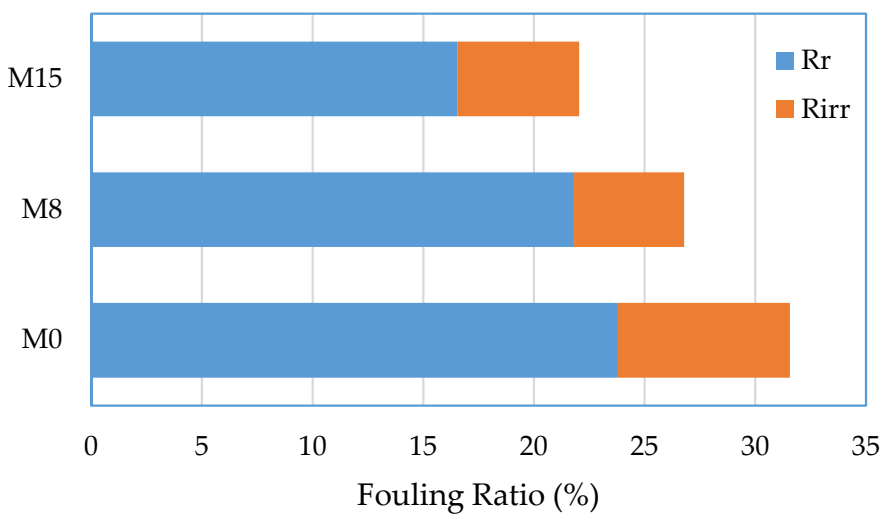

Figure 9. Summary of percentage of total fouling ratio (Rt), reversible fouling ratio (Rr), and irreversible fouling ratio (Rir) of the prepared membranes during the humic acid ultrafiltration. 


\section{- Cadmium Removal}

The performances of the membranes in Cadmium $(\mathrm{Cd})$ removal were investigated by treating solutions containing $10^{-3} \mathrm{~mol} \mathrm{~L}^{-1}$ of $\mathrm{Cd}^{2+}$ at various $\mathrm{pH}$ values as shown in Figure 10.

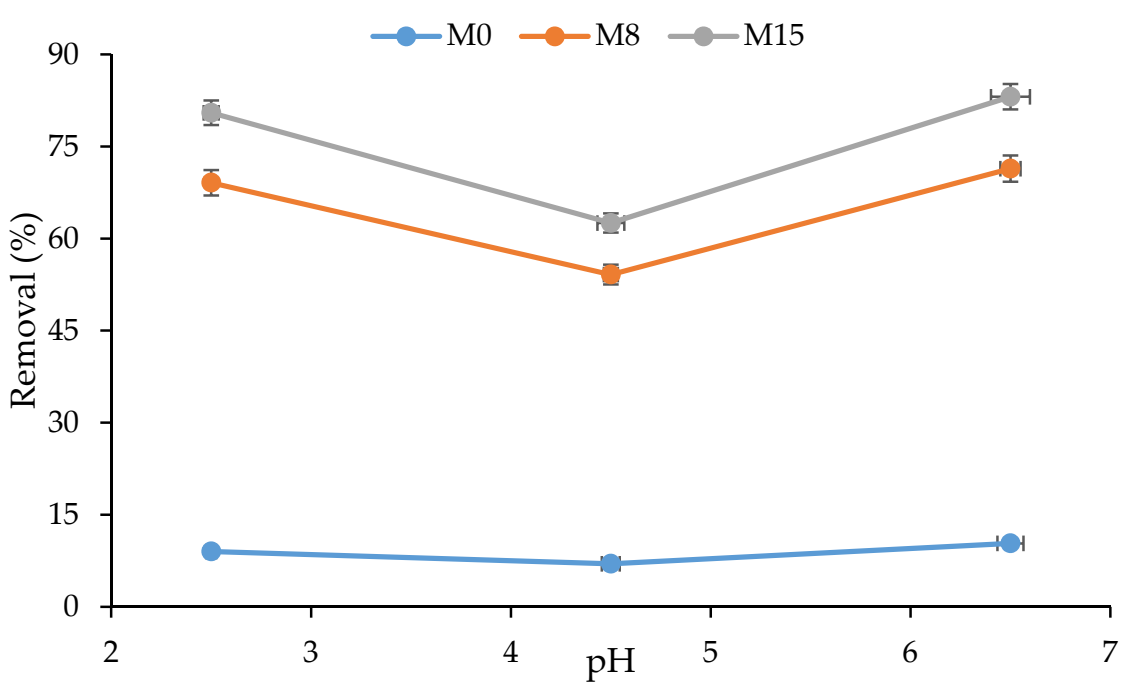

Figure 10. Effect of $\mathrm{pH}$ variation on percentage removal of cadmium for the prepared membranes.

Experiments were performed at values of $\mathrm{pH}$ below 6.5 in order to avoid the precipitation reactions between $\mathrm{OH}$ - anion and $\mathrm{Cd}^{2+}$ cation in form $\mathrm{Cd}(\mathrm{OH})^{2}$. Results confirmed the inefficacy of CA in Cd removal (\% removal $<10 \%)$ with a minimal ion binding capacity related to the presence of hydroxyl and carboxyl functional groups. The blending of CA with PAA led to drastic improvement of the performance of the membranes in $\mathrm{Cd}$ remediation exploiting the carboxylic group introduced by PAA easily ionisable in aqueous solutions [53,54]. Thus, the rejection percentage increased proportionally with the PAA amount in the starting casting solution. Moreover, the maximum removal rate was observed for M15 with values of $80.5 \%$ and $83.1 \%$ at $\mathrm{pH}$ of 2.5 and 6.5 , respectively, reduced from ca. $20 \%$ at a pH of 4.5 [55]. A similar trend was observed for membrane prepared using a PAA concentration in the dope solution of $8 \mathrm{wt}$. \% (M8). Usually, the $\mathrm{pH}$ value has a strong influence on ion rejection by altering the net charge of the membrane surface affecting ultimately the interactions between the contaminants and the membrane [56]. At high $\mathrm{pH}$, the carboxylic groups resulted in ionized form favouring the metal-ion complexation or ionic interactions $\left(-\mathrm{O} \cdots \mathrm{Cd}^{2+} \ldots \mathrm{O}-\right)$, thus increasing the degree of $\mathrm{Cd}$ removal consequently. At a pH of 4.5, the carboxylic groups are neutralized (isoelectric point) and the membrane-Cd interactions are minimized. At low $\mathrm{pH}$, the membrane shifts to positive charge generating repulsion interactions between the membrane surface and the cations of $\mathrm{Cd}^{2+}$.

\section{Conclusions}

The aim of this work was the development of fouling-resistant UF membranes for Cd remediation via blending to synergically exploit the flexibility of CA with the complexing properties of PAA. The strong hydrogen interactions between the two polymers observed with FT-IR and the presence of a single peak in DSC results confirmed the homogeneity of the blending of CA and PAA into the membranes prepared via NIPS. The membranes presented asymmetric and highly porous structures with morphologies affected by the PAA concentration. In fact, the porosity enhanced from $44.5 \%$ to $75.6 \%$ by raising the concentration of the PAA from $0 \mathrm{wt}$. $\%$ to $15 \mathrm{wt}$. \%. Measurements of contact angle and the pure water flux evidenced the improvement of the hydrophilicity of the membrane by introducing PAA in the CA structure. The ultimate result is that the membrane prepared 
with a higher content of PAA (M15) showed superior properties in both permeability and HA rejection. Benefits of blending CA with PAA were observed also in terms of antifouling properties, allowing for effective flux recovery of membrane fouled by treating HA solutions. In fact, the total fouling ratio (Rt) was remarkably reduced owing to the repulsive interactions between the foulants (HA) and the surface of the membranes made of CA blended with PAA rich of carboxylic groups. Concisely, a remarkable mitigation of total fouling ratio from $31.5 \%$ for CA membrane (M0) to $22 \%$ for M15 was observed. Moreover, PAA provided functional properties to the membrane, enabling their employment in the efficient remediation of heavy metal-contaminated aqueous solution. In fact, the $\mathrm{Cd}$ rejection raised with the concentration of PAA into the membrane hitting for M15 values above the $80 \%$, whereas the neat CA (M0) was inefficient in the Cd removal. Overall, the blending of CA with PAA was found to be beneficial in the development of antifouling UF membranes useful in the remediation of heavy metal contaminated waterbodies

Author Contributions: I.O.: Investigation; Writing; Formal Analysis; Data Curatio; Y.G.: WritingOriginal Draft Preparation; C.U.: Formal Analysis; Data Curation; Writing-Original Draft Preparation; Writing—Review and Editing; S.S.: Writing-Original Draft Preparation; Writing-Review \& Editing; S.M.: Formal Analysis; A.H.: Writing—Review and Editing; E.F.: Supervision; A.F.: Supervision; Writing-Original Draft Preparation; Writing-Review and Editing. All authors have read and agreed to the published version of the manuscript.

Funding: This research received no external funding.

Institutional Review Board Statement: Not applicable.

Informed Consent Statement: Not applicable.

Data Availability Statement: Data will be made available on request.

Acknowledgments: The authors wish to thank the Tunisian Ministry of Higher Education and Scientific Research for the financial support of this work and the Institute on Membrane Technology (ITM-CNR), Italy, for providing some characterization tools.

Conflicts of Interest: The authors declare no conflict of interest.

\section{References}

1. Warsinger, D.M.; Chakraborty, S.; Tow, E.W.; Plumlee, M.H.; Bellona, C.; Loutatidou, S.; Karimi, L.; Mikelonis, A.M.; Achilli, A.; Ghassemi, A.; et al. A review of polymeric membranes and processes for potable water reuse. Prog. Polym. Sci. 2018, 81, $209-237$. [CrossRef]

2. Fiksdal, L.; Leiknes, T. The effect of coagulation with MF/UF membrane filtration for the removal of virus in drinking water. J. Membr. Sci. 2006, 279, 364-371. [CrossRef]

3. Gao, W.; Liang, H.; Ma, J.; Han, M.; Chen, Z.; Han, Z.; Li, G. Membrane fouling control in ultrafiltration technology for drinking water production: A review. Desalination 2011, 272, 1-8. [CrossRef]

4. Apel, Y.P.; Bobreshova, O.V.; Volkov, A.V.; Volkov, V.V.; Nikonenko, V.V.; Stenina, I.A.; Filippov, A.N.; Yampolskii, Y.P.; Yaroslavtsev, A.B. Prospects of Membrane Science Development. Membr. Membr. Technol. 2019, 1, 45-63. [CrossRef]

5. Cassano, A.; Drioli, E.; Molinari, R.; Bertolutti, C. Quality improvement of recycled chromium in the tanning operation by membrane processes. Desalination 1997, 108, 193-203. [CrossRef]

6. Chaufer, B.; Deratani, A. Removal of metal ions by complexation-ultrafiltration using water-soluble macromolecules: Perspective of application to wastewater treatment. Nucl. Chem. Waste Manag. 1988, 8, 175-187. [CrossRef]

7. Huang, Y.; Feng, X. Polymer-enhanced ultrafiltration: Fundamentals, applications and recent developments. J. Membr. Sci. 2019, 586, 53-83. [CrossRef]

8. Zhu, Y.; Fan, W.; Zhou, T.; Li, X. Removal of chelated heavy metals from aqueous solution: A review of current methods and mechanisms. Sci. Total Environ. 2019, 678, 253-266. [CrossRef]

9. Shi, X.; Tal, G.; Hankins, N.P.; Gitis, V. Fouling and cleaning of ultrafiltration membranes: A review. J. Water Process Eng. 2014, 1, 121-138. [CrossRef]

10. Kirschner, A.Y.; Cheng, Y.-H.; Paul, D.R.; Field, R.W.; Freeman, B.D. Fouling mechanisms in constant flux crossflow ultrafiltration. J. Membr. Sci. 2019, 574, 65-75. [CrossRef]

11. Zhao, X.; Zhang, R.; Liu, Y.; He, M.; Su, Y.; Gao, C.; Jiang, Z. Antifouling membrane surface construction: Chemistry plays a critical role. J. Membr. Sci. 2018, 551, 145-171. [CrossRef] 
12. Ontiveros, M.A.; Quintero, Y.; Llanquilef, A.; Morel, M.; Martínez, L.A.; García, A.G.; Garcia, A. Anti-Biofouling and Desalination Properties of Thin Film Composite Reverse Osmosis Membranes Modified with Copper and Iron Nanoparticles. Materials 2019, 12, 2081. [CrossRef] [PubMed]

13. Zhu, K.; Zhang, S.; Luan, J.; Mu, Y.; Du, Y.; Wang, G. Fabrication of ultrafiltration membranes with enhanced antifouling capability and stable mechanical properties via the strategies of blending and crosslinking. J. Membr. Sci. 2017, 539, 116-127. [CrossRef]

14. Zhao, C.; Lv, J.; Xu, X.; Zhang, G.; Yang, Y.; Yang, F. Highly antifouling and antibacterial performance of poly (vinylidene fluoride) ultrafiltration membranes blending with copper oxide and graphene oxide nanofillers for effective wastewater treatment. $J$. Colloid Interface Sci. 2017, 505, 341-351. [CrossRef]

15. Nishigochi, S.; Ishigami, T.; Maruyama, T.; Hao, Y.; Ohmukai, Y.; Iwasaki, Y.; Matsuyama, H. Improvement of Antifouling Properties of Polyvinylidene Fluoride Hollow Fiber Membranes by Simple Dip Coating of Phosphorylcholine Copolymer via Hydrophobic Interactions. Ind. Eng. Chem. Res. 2014, 53, 2491-2497. [CrossRef]

16. Huner, I.D.; Gulec, H.A. Fouling behavior of poly(ether)sulfone ultrafiltration membrane during concentration of whey proteins: Effect of hydrophilic modification using atmospheric pressure argon jet plasma. Colloids Surf. B Biointerfaces 2017, 160, 510-519. [CrossRef]

17. Santoro, S.; Drioli, E.; Figoli, A. Development of Novel ECTFE Coated PP Composite Hollow-Fiber Membranes. Coatings 2016, 6, 40. [CrossRef]

18. Xiao, Z.; Guo, H.; He, H.; Liu, Y.; Li, X.; Zhang, Y.; Yin, H.; Volkov, A.V.; He, T. Unprecedented scaling/fouling resistance of omniphobic polyvinylidene fluoride membrane with silica nanoparticle coated micropillars in direct contact membrane distillation. J. Membr. Sci. 2020, 599, 117819. [CrossRef]

19. Nady, N.; Franssen, M.C.R.; Zuilhof, H.; Eldin, M.S.M.; Boom, R.; Schroën, K. Modification methods for poly(arylsulfone) membranes: A mini-review focusing on surface modification. Desalination 2011, 275, 1-9. [CrossRef]

20. Wu, H.; Li, T.; Liu, B.; Chen, C.; Wang, S.; Crittenden, J.C. Blended PVC/PVC-g-PEGMA ultrafiltration membranes with enhanced performance and antifouling properties. Appl. Surf. Sci. 2018, 455, 987-996. [CrossRef]

21. Zhang, X.; Wang, Z.; Chen, M.; Ma, J.; Chen, S.; Wu, Z. Membrane biofouling control using polyvinylidene fluoride membrane blended with quaternary ammonium compound assembled on carbon material. J. Membr. Sci. 2017, 539, 229-237. [CrossRef]

22. Bussi, Y.; Golan, S.; Dosoretz, C.G.; Eisen, M.S. Synthesis, characterization and performance of polystyrene/PMMA blend membranes for potential water treatment. Desalination 2018, 431, 35-46. [CrossRef]

23. Zeng, J.; Zhang, Z.; Dong, Z.; Ren, P.; Li, Y.; Liu, X. Fabrication and characterization of an ion-imprinted membrane via blending poly(methyl methacrylate-co-2-hydroxyethyl methacrylate) with polyvinylidene fluoride for selective adsorption of Ru(III). React. Funct. Polym. 2017, 115, 1-9. [CrossRef]

24. Park, S.W.; Bediako, J.K.; Song, M.H.; Choi, J.W.; Lee, H.C.; Yun, Y.S. Facile fabrication of polyacrylic acid-polyvinyl chloride composite adsorbents for the treatment of cadmium-contaminated wastewater. J. Environ. Chem. Eng. 2018, 6, 2401-2408. [CrossRef]

25. Hu, D.; Lian, Z.; Xian, H.; Jiang, R.; Wang, N.; Weng, Y.; Peng, X.; Wang, S.; Ouyang, X. Adsorption of Pb(II) from aqueous solution by polyacrylic acid grafted magnetic chitosan nanocomposite. Int. J. Biol. Macromol. 2020, 154, 1537-1547. [CrossRef] [PubMed]

26. Fu, H.; Kobayashi, T. Self-assembly functionalized membranes with chitosan microsphere/polyacrylic acid layers and its application for metal ion removal. J. Mater. Sci. 2010, 45, 6694-6700. [CrossRef]

27. Ounifi, I.; Saidi, N.; Kahloul, M.; Sealeyd, K.S.; Hafiane, A.; Ferjani, E. Synthesis and characterization of ultrafiltration membranes by phase inversion and by uropathogenic Escherichia coli retention performance. Desalin. Water Treat. 2019, 163, $109-117$. [CrossRef]

28. Suthabanditpong, W.; Takai, C.; Razavi-Khosroshahi, H.; Okada, Y.; El-Salmawy, M.S.; Fuji, M. Influence of CaCO 3 pore-forming agent on porosity and thermal conductivity of cellulose acetate materials prepared by non-solvent induced phase separation. Adv. Powder Technol. 2019, 30, 207-213. [CrossRef]

29. Santoro, S.; Sebastian, V.; Moro, A.J.; Portugal, C.A.M.; Lima, J.C.; Coelhoso, I.M.; Crespo, J.G.; Mallada, R. Development of fluorescent thermoresponsive nanoparticles for temperature monitoring on membrane surfaces. J. Colloid Interface Sci. 2017, 486, 144-152. [CrossRef]

30. Russo, F.; Bulzomì, M.; Di Nicolò, E.; Ursino, C.; Figoli, A. Enhanced Anti-Fouling Behavior and Performance of PES Membrane by UV Treatment. Processes 2021, 9, 246. [CrossRef]

31. Ounifi, I.; Ursino, C.; Santoro, S.; Chekir, J.; Hafiane, A.; Figoli, A.; Ferjani, E. Cellulose Acetate Nanofiltration Membranes for Cadmium Remediation. J. Membr. Sci. Res. 2020, 6, 226-234.

32. Guo, J.; Kim, J. Modifications of polyethersulfone membrane by doping sulfated- $\mathrm{TiO}_{2}$ nanoparticles for improving anti-fouling property in wastewater treatment. RSC Adv. 2017, 7, 33822-33828. [CrossRef]

33. Liu, Y.; Yue, X.; Zhang, S.; Ren, J.; Yang, L.; Wang, Q.; Wang, G. Synthesis of sulfonated polyphenylsulfone as candidates for antifouling ultrafiltration membrane. Sep. Purif. Technol. 2012, 98, 298-307. [CrossRef]

34. Ramsay, H.; Simon, D.; Steele, E.; Hebert, A.; Oleschuk, R.D.; Stamplecoskie, K.G. The power of fluorescence excitation-emission matrix (EEM) spectroscopy in the identification and characterization of complex mixtures of fluorescent silver clusters. RSC Adv. 2018, 8, 42080-42086. [CrossRef] 
35. Ahmad, A.; Waheed, S.; Khan, S.M.; e-Gul, S.; Shafiq, M.; Farooq, M.; Sanaullah, K.; Jamil, T. Effect of silica on the properties of cellulose acetate/polyethylene glycol membranes for reverse osmosis. Desalination 2015, 355, 1-10. [CrossRef]

36. Liu, C.; Bai, R. Preparation of chitosan/cellulose acetate blend hollow fibers for adsorptive performance. J. Memb. Sci. 2005, 267, 68-77. [CrossRef]

37. Sánchez-Márquez, J.A.; Fuentes-Ramírez, R.; Cano-Rodríguez, I.; Gamiño-Arroyo, Z.; Rubio-Rosas, E.; Kenny, J.M.; Rescignano, N. Membrane Made of Cellulose Acetate with Polyacrylic acid Reinforced with Carbon Nanotubes and Its Applicability for Chromium Removal. Int. J. Polym. Sci. 2015, 2015, 320631. [CrossRef]

38. Defieuw, G.; Groeninckx, G.; Reynaers, H. Miscibility and morphology of binary polymer blends of polycaprolactone with solution-chlorinated polyethylenes. Polymer 1989, 30, 595-603. [CrossRef]

39. Bragança, F.C.; Rosa, D.S. Thermal, mechanical and morphological analysis of poly( $\varepsilon$-caprolactone), cellulose acetate and their blends. Polym. Adv. Technol. 2003, 14, 669-675. [CrossRef]

40. Arthanareeswaran, G.; Thanikaivelan, P.; Srinivasn, K.; Mohan, D.; Rajendran, M. Synthesis, characterization and thermal studies on cellulose acetate membranes with additive. Eur. Polym. J. 2004, 40, 2153-2159. [CrossRef]

41. van de Witte, P.; Dijkstra, P.J.; van den Berg, J.W.A.; Feijen, J. Phase separation processes in polymer solutions in relation to membrane formation. J. Membr. Sci. 1996, 117, 1-31. [CrossRef]

42. Tan, X.; Rodrigue, D. A Review on Porous Polymeric Membrane Preparation. Part I: Production Techniques with Polysulfone and Poly (Vinylidene Fluoride). Polymers 2019, 11, 1160. [CrossRef]

43. Guillen, G.R.; Pan, Y.; Li, M.; Hoek, E.M.V. Preparation and Characterization of Membranes Formed by Nonsolvent Induced Phase Separation: A Review. Ind. Eng. Chem. Res. 2011, 50, 3798-3817. [CrossRef]

44. Smolders, C.A.; Reuvers, A.J.; Boom, R.M.; Wienk, I.M. Microstructures in phase-inversion membranes. Part 1. Formation of macrovoids. J. Membr. Sci. 1992, 73, 259-275. [CrossRef]

45. Guillen, G.R.; Ramon, G.Z.; Kavehpour, H.P.; Kaner, R.B.; Hoek, E.M.V. Direct microscopic observation of membrane formation by nonsolvent induced phase separation. J. Membr. Sci. 2013, 43, 212-220. [CrossRef]

46. Wei, Q.; Li, J.; Qian, B.; Fang, B.; Zhao, C. Preparation, characterization and application of functional polyethersulfone membranes blended with poly (acrylic acid) gels. J. Membr. Sci. 2009, 337, 266-273. [CrossRef]

47. Sierra, M.M.D.; Giovanela, M.; Parlanti, E.; Soriano-Sierra, E.J. Fluorescence fingerprint of fulvic and humic acids from varied origins as viewed by single-scan and excitation/emission matrix techniques. Chemosphere 2005, 58, 715-733. [CrossRef]

48. Yuan, W.; Zydney, A.L. Humic acid fouling during microfiltration. J. Membr. Sci. 1999, 157, 1-12. [CrossRef]

49. Katsoufidou, K.; Yiantsios, S.G.; Karabelas, A.J. A study of ultrafiltration membrane fouling by humic acids and flux recovery by backwashing: Experiments and modeling. J. Membr. Sci. 2005, 266, 40-50. [CrossRef]

50. Li, K.; Li, S.; Huang, T.; Dong, C.; Li, J.; Zhao, B.; Zhang, S. Chemical Cleaning of Ultrafiltration Membrane Fouled by Humic Substances: Comparison between Hydrogen Peroxide and Sodium Hypochlorite. Int. J. Environ. Res. Public Health 2019, 16, 2568. [CrossRef]

51. Panda, S.R.; Mukherjee, M.; De, S. Preparation, characterization and humic acid removal capacity of chitosan coated iron-oxidepolyacrylonitrile mixed matrix membrane. J. Water Process Eng. 2015, 6, 93-104. [CrossRef]

52. Ahmad, A.L.; Pang, W.Y.; Shafie, Z.M.H.M.; Zaulkiflee, N.D. PES/PVP/ $\mathrm{TiO}_{2}$ mixed matrix hollow fiber membrane with antifouling properties for humic acid removal. J. Water Process Eng. 2019, 31, 100827-100835. [CrossRef]

53. Okieimen, F.E.; Sogbaike, C.E.; Ebhoaye, J.E. Removal of cadmium and copper ions from aqueous solution with cellulose graft copolymers. Sep. Purif. Technol. 2005, 44, 85-89. [CrossRef]

54. García, A.; Rodríguez, B.; Oztürk, D.; Rosales, M.; Diaz, D.I.; Mautner, A. Incorporation of CuO nanoparticles into thin-film composite reverse osmosis membranes (TFC-RO) for antibiofouling properties. Polym. Bull. 2018, 75, 2053-2069. [CrossRef]

55. Lam, B.; Déon, S.; Morin-Crini, N.; Crini, G.; Fievet, P. Polymer-enhanced ultrafiltration for heavy metal removal: Influence of chitosan and carboxymethyl cellulose on filtration performances. J. Clean. Prod. 2018, 171, 927-933. [CrossRef]

56. Deshmukh, S.S.; Childress, A.E. Zeta potential of commercial RO membranes: Influence of source water type and chemistry. Desalination 2001, 140, 87-95. [CrossRef] 